\title{
Ubc9 interacts with chicken ovalbumin upstream promoter-transcription factor I and represses receptor-dependent transcription
}

\author{
S Kobayashi ${ }^{\star 1}$, H Shibata* ${ }^{* 1,2}$, I Kurihara*1, K Yokota ${ }^{1}$, N Suda ${ }^{1}$, I Saito ${ }^{1,2}$ and \\ T Saruta ${ }^{1}$ \\ ${ }^{1}$ Department of Internal Medicine, School of Medicine, Keio University, 35 Shinanomachi, Shinjuku-ku, Tokyo 160-8582, Japan \\ ${ }^{2}$ Health Center, School of Medicine, Keio University, 35 Shinanomachi, Shinjuku-ku, Tokyo 160-8582, Japan
}

(Requests for offprints should be addressed to Hirotaka Shibata; Email: hiro-405@cb3.so-net.ne.jp)

${ }^{*}$ (S Kobayashi, H Shibata and I Kurihara contributed equally to this work)

\begin{abstract}
Chicken ovalbumin upstream promoter-transcription factors (COUP-TFs) are orphan receptors involved in regulation of neurogenesis and organogenesis. COUP-TF family members are generally considered to be transcriptional repressors and several mechanisms have been proposed to underlie this activity. To explore novel transcriptional coregulators for COUP-TFs, we used the COUP-TFI as bait in a yeast two-hybrid screen of an adrenocortical adenoma cDNA library. We have identified Ubc9, a class E2 conjugating enzyme of small ubiquitin-related modifier (SUMO)-1 as a COUP-TFI corepressor. Ubc9 interacts with COUP-TFI in yeast and in glutathione S-transferase pulldown and coimmunoprecipitation assays. Fluorescence imaging studies show that both Ubc9 and COUP-TFI are colocalized in the nuclei of transfected COS-1 cells. The C-terminal region of Ubc9 encoding amino acids 59-158 interacts with the C-terminus of COUP-TFI encoding amino acids 383-403, in which transcriptional repression domains are located. Mammalian one-hybrid assays utilizing a variety of Ubc9 fragments fused to Gal4 DNA-binding domain show that a Ubc9 fragment encoding amino acids 1-89 contains autonomous transferrable repression domain. Transfection of Ubc9 into COS-1 cells markedly enhances transcriptional repression by Gal4 DNA-binding domain-fused to COUP-TFI(155-423), but not by Gal4-COUP-TFI(155-388) which lacks a repressor domain. Coexpression of a C-terminal deletion mutant of Ubc9(1-58), which fails to interact with COUP-TFI, but retains a transcriptional repression domain, has no effect on Gal4-COUP-TFI-mediated repression activity. These findings indicate that interaction of Ubc9 with COUP-TFI is crucial for the corepressor function of Ubc9. Overexpression of Ubc9 similarly enhances COUP-TFI-dependent repression of the promoter activity of the bovine CYP17 gene encoding steroid 17 $\alpha$-hydroxylase. In addition, the C93S mutant of Ubc9, which abrogates SUMO-1 conjugation activity, continues to function as a COUP-TFI corepressor. Our studies indicate that Ubc9 functions as a novel COUP-TFI corepressor, the function of which is distinct from its SUMO-1 conjugating enzyme activity.
\end{abstract}

Journal of Molecular Endocrinology (2004) 32, 69-86

\section{Introduction}

Chicken ovalbumin upstream promotertranscription factors (COUP-TFs) are orphan members of the nuclear receptor superfamily for which a ligand has yet to be identified (Wang et al.
1989, Ladias \& Karathanasis 1991, Malik \& Karathanasis 1995, Tsai \& Tsai 1997). COUPTFI/EAR3 (encoded by NR2F1) and COUPTFII/ARP-1 (encoded by NR2F2) are closely related transcription factors in mammals and are involved in the regulation of crucial biological 
processes, such as neurogenesis, organogenesis and determination of cell fate (Pereira et al. 1995, Tsai \& Tsai 1997, Cooney et al. 2001).

Although COUP-TF was originally identified as an activator of the chicken ovalbumin gene, COUP-TF family members are generally considered to be repressors of ligand-activated nuclear receptors, such as retinoic acid (RAR), thyroid hormone (TR), oestrogen and vitamin D3 receptors (VDR), and peroxisome proliferator-activated receptor a (Cooney et al. 1992, Tsai \& Tsai 1997). Several mechanisms have been proposed to explain the COUP-TF-mediated repression activity (Berrodin et al. 1992, Kliewer et al. 1992a,b, Tran et al. 1992, Cooney et al. 1993, Casanova et al. 1994, Leng et al. 1996, Achatz et al. 1997, Shibata et al. $1997 a, 2003 b)$. COUP-TFs are able to bind to a variety of direct repeats, such as DR1, DR3, DR4 and DR5 of the AGGTCA motif, which are recognized by RAR, THR and VDR. This ability makes COUP-TFs capable of competing for the response elements of these receptors, thus acting as passive repressors of the transcriptional activation induced by them. Another mechanism of passive repression by COUP-TFs involves their ability to heterodimerize with the 9-cis retinoic acid receptor, reducing its availability for other nuclear receptors that use it as a partner. COUP-TFs also function as repressors by quenching transactivator-dependent transcription and transrepression of activated transcription. In addition, COUP-TFs, like THR and RAR, are able actively to repress the basal promoter activity of several target genes, through interaction with corepressors such as nuclear receptor corepressor (N-CoR) and silencing mediator for retinoid and thyroid hormone receptors (SMRT) in mammalian cells (Bailey et al. 1997, Shibata et al. 1997a). Therefore, COUP-TFI can function as a repressor in vivo by utilizing corepressors that are common for members of the THR and RAR subfamily.

Our recent studies have suggested that COUPTFs and steroidogenic factor-1 (SF-1) have key roles in the transcriptional regulation of steoridogenic P450 genes (Shibata et al. 1998, 2000a,b, 2001, Shibata et al. 2003a,b). Transfection studies showed that SF-1 activated and COUP-TFs repressed bovine CYP17 gene transcription as a result of mutually exclusive binding to the promoter in mouse adrenocortical Y-1 cells. In addition, levels of expression of COUP-TFI have been shown to be highly correlated with those of N-CoR, but inversely correlated with those of CYP17 in human adrenocortical adenomas, indicating that COUP-TFI may play a crucial part in the regulation of steroidogenesis in adrenocortical adenomas. To search for novel coregulator proteins for COUP-TFI, we screened COUP-TFinteracting proteins from a human adrenocortical tumour cDNA library with a yeast two-hybrid system and a COUP-TFI fragment encoding amino acids 55-423 as bait. We then identified Ubc9 (Kovalenko et al. 1996, Wang et al. 1996), the human homologue of yeast class E2 small ubiquitin-related modifier (SUMO)-1-conjugating enzyme.

SUMO-1 (Melchior 2000, Hay 2001, Jackson 2001, Muller et al. 2001, Seeler \& Dejean 2001, Wilson \& Rangasamy 2001) is known to be covalently conjugated to a variety of cellular substrates, and this modification utilizes a threestep enzymatic pathway analogous to the pathway of ubiquitin conjugation. The enzymes for these three steps are Aos1-Uba2 as the activating enzyme (class E1), Ubc9 as the conjugating enzyme (class E2), and PIAS 1 (Hochstrasser 2001, Jackson 2001, Kahyo et al. 2001), RanBP2 (Pichler et al. 2002) and PC2 (Kagey et al. 2003) as the SUMO-1 ligase (class E3), which has recently been identified. Ubc9 also has several biological functions and not only catalyses SUMO-1 conjugation of different proteins, but also is particularly crucial in the regulation of transcription. Available data currently implicate SUMO in the regulation of proteinprotein interactions (Matunis et al. 1998), subcellular nuclear localization (Seeler \& Dejean 2001, Pichler \& Melchior 2002), protein-DNA interactions (Goodson et al. 2001) and enzymatic activity (Hardeland et al. 2002), and there is also evidence that SUMO can act as an antagonist of ubiquitin (Desterro et al. 1998, Hoege et al. 2002). Recent reports indicate that SUMO modification provides not merely modulatory but actually inhibitory domain function (Iniguez-Lluhi \& Pearce 2000, Kim et al. 2002, Yang et al. 2002); indeed, it is notable that several well-characterized repressors contain SUMO consensus sites within their repression domains.

In the present study, overexpression of Ubc9 in transfected COS-1 cells enhanced COUP-TFImediated repression activity of the bovine CYP17 promoter in a trichostatin A-insensitive manner. 
A

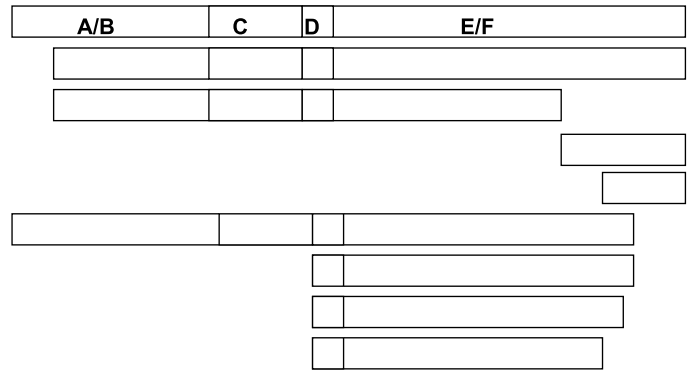

COUP-TFI (1-423)

COUP-TFI (55-423)

COUP-TFI (55-315)

COUP-TFI (315-423)

COUP-TFI (378-423)

COUP-TFI (1-403)

COUP-TFI (154-403)

COUP-TFI (154-383)

COUP-TFI (154-363)

\section{B}
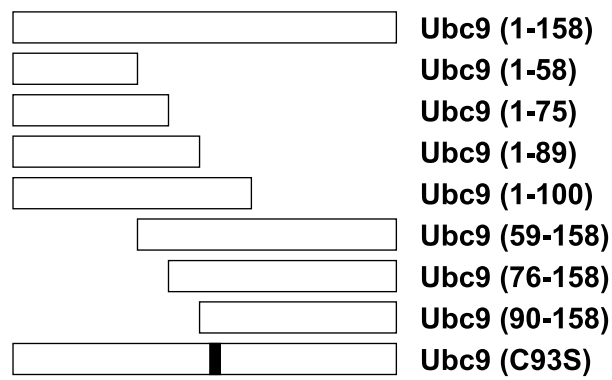

Figure 1 Diagram of various deletion mutants of (A) COUP-TFI and (B) Ubc9. (A) The COUP-TFI fragments shown were cloned into the pGBKT7, pcDNA3.1/His and pCMV-BD expression vectors as described in Materials and methods. Based on other nuclear hormone receptors as a reference, the sequences from amino acids 1-85, 86-149, 150-183 and 184-423 have been designated domains $A / B, C, D$ and $E / F$, respectively. (B) The Ubc9 fragments shown were cloned into the pGADT7, pcDNA3.1/His and pCMV-BD expression vectors as described in Materials and Methods.

The corepressor activities of Ubc9 were not abolished by the C93S substitution that abrogates SUMO-1 conjugating enzyme activity. We propose that Ubc9 can function as a novel COUP-TFI corepressor, the function of which is independent of SUMO-1 conjugating enzyme activity.

\section{Materials and methods}

\section{Plasmid constructs}

The expression plasmids pRSV-COUP-TFI, pFLCOUP-TFI, pFL-COUP-TFII, pRSV-Gal4COUP-TFI (155-423), pRSV-Gal4-COUPTFI $\Delta 35$, pRSV-Gal4(1-147), pRSV-Gal4-VP16, pAS1 cyh2-TR $\beta 168-456$ and p4 $\times$ Gal4-tk-Luc have been described previously (Leng et al. 1996, Shibata et al. 1997a). pGBT9-Ad4BP/SF-1 and pGBT9-DAX-1 were generous gifts from Dr K Morohashi (National Institute for Basic Biology, Japan).

A diagram of various deletion mutants of COUP-TFI and Ubc9 is shown in Fig. 1.
The Gal4 DBD-COUP-TFI(55-423) yeast expression plasmid [pGBKT7-COUP-TFI(55423)] was constructed by inserting the SmaI-EcoRI blunt-ended fragment of pFL-COUP-TFI into the SmaI site of pGBKT7 vector (Clontech, Palo Alto, CA, USA). pGBKT7-COUP-TFI(55-315) was constructed by SalI digestion of pGBKT7-COUPTFI(55-423) followed by self-ligation with T4 DNA ligase. The COUP-TFI deletion mutant series COUP-TFI(378-423), COUP-TFI(315423), COUP-TFI(154-403), COUP-TFI(154-383), COUP-TFI(154-363) and COUP-TFI(1-403) were generated by PCR, introducing flanking restriction enzyme sites, thereby subcloning into the pGBKT7 yeast expression vector (Clontech). pGBKT7-COUP-TFII was constructed by inserting the EcoRI fragment of pFL-COUP-TFII into the EcoRI site of pGBKT7 vector. pGADT7Ubc9(1-158) was cloned as a COUP-TFIinteracting protein by using a yeast two-hybrid system. pGADT7-Ubc9(1-58) was constructed by PmeI-SpeI digestion (filled) of pGADT7-Ubc9(1158), followed by ligation with T4 DNA ligase. 
pGADT7-Ubc9(C93S) was constructed with a site-directed mutagenesis kit. Mutagenesis of Ubc9 was performed with the Transformer Site Directed Mutagenesis kit (Clontech) and the mutagenesis oligonucleotide 5'-CTTCGGGGACAGTGTCC CTGTCGATCTTAGAGG-3'. The underlined sequence corresponds to the Cys (TGG) to Ser (TCG) codon change. The Ubc9 deletion mutant series Ubc9(1-75), Ubc9(1-89), Ubc9(1-100), Ubc9(59-158), Ubc9(76-158), and Ubc9(90-158) were generated by PGR, introducing flanking restriction enzyme sites, thereby subcloning into the pGADT7 yeast expression vector (Clontech) and pCMV-BD mammalian expression vector (Stratagene, La Jolla, CA, USA). pcDNA3.1/HisUbc9(1-158), pcDNA3.1/His-Ubc9(C93S) and pcDNA3.1/His-Ubc9(1-58) were constructed by inserting the EcoRI-XhoI fragment of pGADT7Ubc9(1-158), pGADT7-Ubc9(C93S) and pGADT7-Ubc9(1-58), respectively, into the EcoRI-XhoI site of pcDNA3.1/His vector (Invitrogen). pCMV-BD-Ubc9(1-158), pCMVBD-Ubc9(C93S), and pCMV-BD-Ubc9(1-58) were constructed by inserting the EcoRI-PstI fragments of pGADT7-Ubc9(1-158), pGADT7Ubc9(C93S) and pGADT7-Ubc9(1-58) into the EcoRI-PstI site of pCMV-BD vector (Stratagene). pGL3-3 CRS2 was constructed by ligating cDNA which was made by annealing two oligonucleotides, 5'-CGCAAAGTCAAGGAGAAGGTCAGGGAA AGTCAAGGAGAAGGTCAGGGAAAGTGAA GGAGAAGGTAGGGCGGG-3' and 5'-TGGAG GGGCGCTGACGTTGTCGTTGACTTTCGG TGACGTTGTGGTTGACTTTCGCTGAGGT TGTGGTTGACTTTGGGGTAG-3', into the KpnI-XhoI site of pGL3 promoter vector (Promega). pEGFP_Ubc9 and pEGFPUbc9(C93S) were constructed by inserting the EcoRI-XhoI fragments of pGADT7-Ubc9 and pGADT7-Ubc9(C93S), respectively, into the EcoRI-Sall site of pEGFP-C2 vector (Clontech). pDsRed-COUP-TFI was generated by PCR, introducing the flanking EcoRI-BamHI site, thereby subcloning into the pDsRed vector (Clontech). The Ubc9(1-158), Ubc9(C93S) and Ubc9(1-58) were subcloned into the EcoRI-XhoI site of pGEX4T-1 vector (Amersham Pharmacia Biotech).

DNA sequencing of all the constructs was confirmed by ABI PRISM dye terminator cycle sequencing analysis (Amersham Pharmacia Biotech).

\section{Cloning of Ubc9 by a yeast two-hybrid system}

Yeast two-hybrid screening was conducted with the MATCHMAKER Two-Hybrid System 3 kit (Clontech) and COUP-TFI (amino acids 55423) as bait. A human adrenocortical tumour cDNA library was prepared as follows. Messenger RNA was prepared from a cortisol-producing adrenocortical adenoma with an OligotexdT30mRNA purification kit (TaKaRa Bio Inc, Tokyo, Japan), and cDNA was synthesized by reverse transcription of the mRNA with an oligo (dT)18 linker. We then transformed E. coli competent cells with the cDNAs by electroporation, and ligated the cDNAs into the pGADT7 vector. Yeast strain AH109 containing pGBKT7-COUPTFI(55-423) was transformed with a human cortisol-producing adrenocortical adenoma cDNA library in pGADT7 (Clontech) and plated on synthetic complete medium lacking tryptophan, adenine, leucine and histidine, as described by Durfee et al. (1993).

$\mathrm{His}^{+}$and $\mathrm{Ade}^{+}$colonies exhibiting $\beta$-galactosidase activity by filter lift assay were further characterized according to the manufacturer's procedure (Clontech). $\quad \beta$-galactosidase activity was determined with chlorophenol red $\beta$-D-galactopyranoside as described previously (Shibata et al. 1997a). To recover the library plasmids, total DNA from the yeast was isolated with a Zymoprep Yeast Plasmid Miniprep kit (Zymo Research, Orange, CA, USA) and used to transform E. coli (HB101) in the presence of ampicillin. To ensure that the correct cDNAs were identified, the library plasmids isolated were transformed into Y187 containing pGBKT7COUP-TFI(55-423) and $\beta$-galactosidase activity was determined. The specificity of the interaction of \#2-4 (Ubc9 1-158), one of the 20 positive clones, with COUP-TFI was determined by mating with Y187, which contains pGBKT7-lamin (Clontech). The $\beta$-galactosidase activity of these diploids was examined by the filter lift and chlorophenol red $\beta$-D-galactopyranoside methods. The sequence of the \#2-4 clone was identical to that of Ubc9, the human homologue of yeast ubiquitin-conjugating enzyme, that had been submitted to GenBank. The yeast two-hybrid system was also used to determine interaction of Ubc9 with COUP-TFI and other nuclear receptors (Fig. 2). 


\section{Mammalian cell culture, transient transfections and luciferase assays}

COS-1 cells were routinely maintained in DMEM (Life Technologies) supplemented with 10\% fetal bovine serum (Life Technologies). Twenty-four hours before transfection, $5 \times 10^{4}$ cells per well of a 24-well dish were plated in the medium. All transfections were carried out using TransFast (Promega) with $0.3 \mu \mathrm{g} /$ well of the luciferase reporter, $0.03 \mu \mathrm{g} /$ well of pRL-TK internal control plasmids and the indicated amounts of expression plasmids as described previously. Cells were transfected with the DNAs indicated by using TransFast (Promega) for each well of the 24-well dish according to the manufacturer's guidelines. Cells were harvested $48 \mathrm{~h}$ after transfection, and cell extracts were assayed for both Firefly and Renilla luciferase activities with a Dual-Luciferase Reporter Assay System (Promega). Relative luciferase activity was determined as ratio of Firefly/Renilla luciferase activities, and data are expressed as the mean ( \pm S.D.) of triplicate values obtained from a representative experiment that was independently repeated at least three times.

\section{Glutathione S-transferase pulldown assay}

Glutathione S-transferase (GST) (pGEX4T-1) protein and GST-Ubc9 [pGEX4T-1-Ubc9(1-158)] fusion protein were expressed and extracted in E. coli $\mathrm{HB} 101$ as described previously (Shibata et al. 1997a). GST pulldown assay was performed as described, with modifications: $50 \mu \mathrm{l}$ glutathionesepharose beads 4B (Amersham Pharmacia Biotech) stored in beads incubation buffer $(50 \mathrm{mM}$ potassium phosphate buffer $\mathrm{pH} 7 \cdot 4,100 \mathrm{mM}$ $\mathrm{NaCl}, 1 \mathrm{mM} \mathrm{MgCl}_{2}, \quad 10 \%$ glycerol and $0 \cdot 1 \%$ Tween 20) were incubated with bacterial extracts containing GST fusion proteins together with beads incubation buffer for $30-60 \mathrm{~min}$ at room temperature. Preparation of bacterial extracts containing GST fusion protein was as described previously (Shibata et al. 1997a). The supernatant was then removed, and the beads were washed twice with beads incubation buffer. In vitrotranslated and -radiolabelled proteins were obtained by using TNT Coupled Reticulocyte Lysate Systems (Promega). Crude lysates were incubated with the beads in $200 \mu \mathrm{l}$ beads incubation buffer for $30 \mathrm{~min}$ at room temperature with a circle rotator.
Finally, the beads were washed five times with $1 \mathrm{ml}$ beads incubation buffer and the proteins were solubilized in SDS loading buffer and analysed on SDS-PAGE (12.5\% polyacrylamide gel). The input lanes contained $20 \%$ of the labelled protein used for binding.

\section{Coimmunoprecipitation assay}

The cells were lysed with lysis buffer $[10 \mathrm{mM}$ Tris-HCl pH 8.0, $150 \mathrm{mM} \mathrm{NaCl,} \mathrm{1 \%} \mathrm{Triton}$ $\mathrm{X}-100,5 \mathrm{mM}$ EDTA, $2 \mathrm{mM}$ phenyl methylsulphonyl fluoride (PMSF)], and western blots were performed before the immunoprecipitation steps. The same samples for the western blots were diluted to $1 \mathrm{ml}$ in immunoprecipitation buffer (20 mM Tris-HCl pH 7·5, 150 mM NaCl, 10 mM dithiothreitol, $5 \mathrm{ng} / \mu \mathrm{l}$ aprotinin, $0.5 \mathrm{mM}$ PMSF, $0 \cdot 1 \%$ Tween 20) and precleared with protein G plus-agarose beads (Santa Cruz Biotechnology, Santa Cruz, CA, USA); antibodies were then added for $1 \mathrm{~h}$. Immune complexes were adsorbed to protein $G$ plus-agarose beads and washed four times in immunoprecipitation buffer. Proteins were then separated on $12.5 \%$ polyacrylamide gels and transferred onto Hybond enhanced chemiluminescence (ECL) nitrocellulose membranes (Amersham Pharmacia Biotech). The primary antibodies used for immunoprecipitation were rabbit polyclonal anti-COUP-TFI antibody (a generous gift from Dr Ming-Jer Tsai, Baylor College of Medicine, Houston, TX, USA) (Wang et al. 1989); those used for the western blots were anti-COUP-TFI or anti-Xpress mouse monoclonal antibodies (Invitrogen).

\section{Fluorescence imaging}

COS-1 cells were transiently transfected with expression vectors of $\mathrm{pEGFP}-\mathrm{Ubc} 9$, and $\mathrm{pDsRed}-$ COUP-TFI. Live cell microscopy of GFP fusion and DsRed fusion proteins was performed on a confocal microscope (Axiovert 100 M, Carl Zeiss Co., Ltd). Imaging for GFP and DsRed was performed by excitation at $488 \mathrm{~nm}$ and $543 \mathrm{~nm}$ respectively from an argon laser, and the emissions were viewed through band passes ranging from 500 to $550 \mathrm{~nm}$ and 550 to $600 \mathrm{~nm}$ respectively, by band-pass regulation with LSM510 (Carl Zeiss Co., Ltd). All images were processed as tiff (tagged 
image file format) on Photoshop $6 \cdot 0$ using standard image processing techniques.

\section{Northern blot analysis}

The human tissue northern blots were obtained from Clontech and hybridized at $42{ }^{\circ} \mathrm{C}$ overnight with ${ }^{32} \mathrm{P}$-labeled cDNA probes of the full-length $1 \cdot 1 \mathrm{~kb} \mathrm{hUbc9}$, full-length $1 \cdot 3 \mathrm{~kb}$ hCOUP-TFI, or $1 \cdot 1 \mathrm{~kb}$ GAPDH (Clontech) cDNAs according to the manufacturer's recommendation. The membranes were washed at a final stringency of $0 \cdot 1 \times$ SSC- $-0 \cdot 1 \%$ SDS at $50{ }^{\circ} \mathrm{C}$ and analysed with a BAS 3000 image scanner (Fuji Film Co.). The mRNA levels were determined by comparison with GAPDH mRNA levels.

\section{Western blot analysis}

Whole-cell lysates were prepared by homogenization in buffer composed of $10 \mathrm{mM}$ Tris- $\mathrm{HCl} \mathrm{pH}$ $8 \cdot 0,150 \mathrm{mM} \mathrm{NaCl}, 1 \%$ Triton X-100, $5 \mathrm{mM}$ EDTA and $2 \mathrm{mM}$ PMSF. After separation by electrophoresis on $12.5 \%$ polyacrylamide gels, the proteins were electroblotted onto nitrocellulose membranes (Hybond ECL, Amersham Pharmacia Biotech) at $200 \mathrm{~V}$. The membranes were then incubated with the following primary antibodies: rabbit polyclonal anti-COUP-TFI antibody (Wang et al. 1989) and mouse monoclonal anti-Xpress IgG (Invitrogen). They were then incubated with horseradish-peroxidase-labeled donkey anti-rabbit IgG (Amersham Pharmacia Biotech) or donkey anti-mouse IgG (Amersham Pharmacia Biotech) secondary antibodies for each of the above, and visualized with the enhanced chemiluminescence western blotting system (Amersham Pharmacia Biotech).

\section{Statistics}

All experiments were performed in triplicate several times. The error bars in the graphs of individual experiments correspond to the S.D. of the triplicate values.

\section{Results}

\section{Identification of Ubc9 as a COUP-TFI-interacting protein by yeast two-hybrid system}

In order to identify proteins that might repress the activity of the COUP-TFI, we used COUP-TFI encoding amino acids 55-423 as bait in a yeast two-hybrid screen with a cDNA library prepared from a human adrenocortical adenoma. In this manner, we identified a full-length clone of Ubc9 that had a $1.1 \mathrm{~kb}$ insert containing an entire open-reading frame encoding 158 amino acids. Ubc9 is an enzyme involved in the conjugation of SUMO-1 to target proteins. To demonstrate that Ubc9 interacts specifically with COUP-TFI, we performed a yeast two-hybrid assay. As shown in Fig. 2, Ubc9 interacted with COUP-TFI, and the interaction was specific, as no interaction between Gal4 DBD-COUP-TFI (amino acids 55-423) fusion and Gal4 activation domain (Gal4 $\mathrm{AD}$; empty vector) was observed (Fig. 2A). In contrast, as a positive control, we showed a strong interaction between Gal4 DBD-COUP-TFI and Gal4 AD-COUP-TFI, because COUP-TFI readily forms homodimers (data not shown). In addition, Ubc9 did not interact with unrelated bait corresponding to lamin (data not shown). Besides interacting with COUP-TFI, Ubc9 also interacted with COUP-TFII and SF-1, but not with DAX-1 or unliganded TR $\beta$ (Fig. 2A).

To identify interaction domains more precisely, various fragments of COUP-TFI and Ubc9 (Fig. 1) were cotransformed in yeast, and $\beta$-galactosidase liquid assays were performed to quantitate the protein-protein interaction (Figs 2B and C). Gal4 DBD-COUP-TFI interacted with most of the N-terminal and C-terminal deletion mutants of Ubc9 except Ubc9(1-58), suggesting that the N-terminal fragment of Ubc9 $(1-58)$ was dispensable for interaction with COUP-TFI (Fig. 2B). In addition, introduction of the C93S substitution into the protein-coding sequence of Ubc9, which renders it incapable of conjugation with SUMO-1, had little effect on the interaction of COUP-TFI with Ubc9, indicating that the SUMO-1conjugating activity of Ubc9 is unnecessary for Ubc9 to interact with COUP-TFI. Subsequently, interaction of several deletion fragments of COUP-TFI with Ubc9 was examined in yeast two-hybrid assays (Fig. 2C). The C-terminal deletion mutant of COUP-TFI encoding amino acids 55-315 did not interact with Ubc9. In addition, both C-terminal COUP-TFI fragments encoding amino acids 315-423 and 378-423 showed significant interaction with Ubc9; however, the interaction between the C-terminal COUP-TFI fragments and Ubc9 (lanes 3 and 4 in Fig. 2C) was 


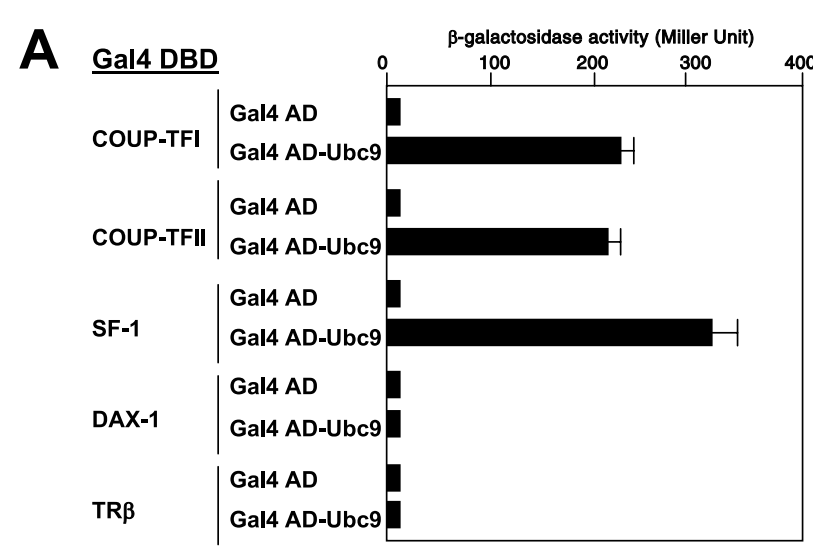

B

Gal4-AD
Ubc9 (1-158)
Ubc9 (1-58)
Ubc9 (1-75)
Ubc9 (1-89)
Ubc9 (1-100)
Ubc9 (59-158)
Ubc9 (76-158)
Ubc9 (90-158)
Ubc9 (C93S)
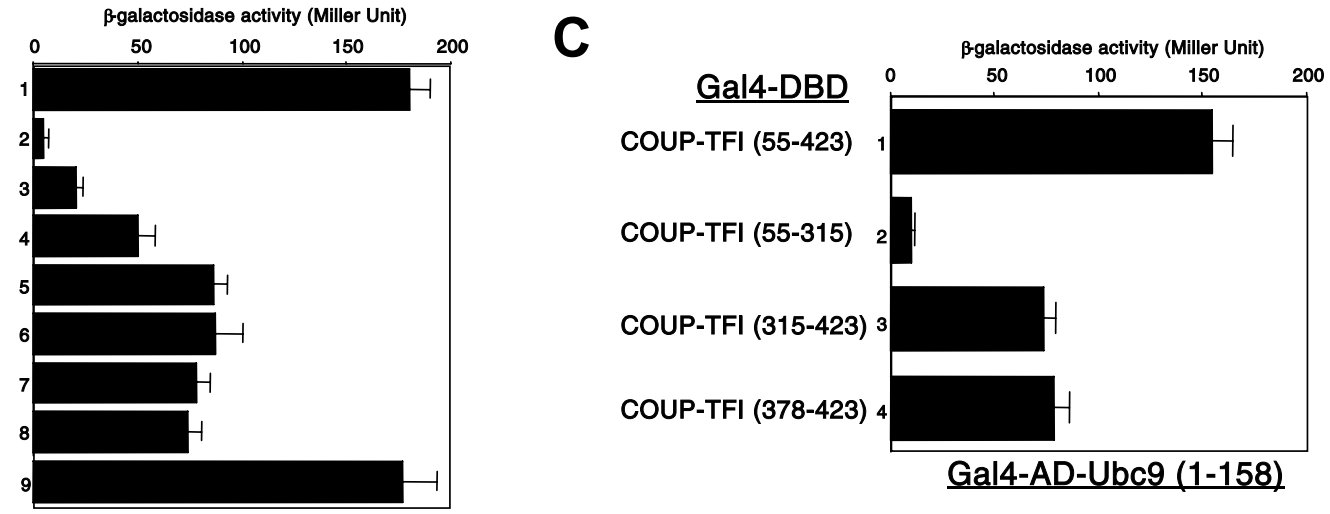

Figure 2 Interaction of Ubc9 with COUP-TFI and several nuclear receptors in yeast two-hybrid assays. (A) Interaction of Ubc9 and various nuclear receptors (COUP-TFI, COUP-TFII, SF-1, DAX-1 and TR $\beta$ ) in yeast. (B) Interaction of various Ubc9 fragments with COUP-TFI(55-423) in yeast. (C) Interaction of various COUP-TFI fragments with Ubc9 in yeast. $\beta$-galactosidase activity was assayed in liquid cultures in three separate experiments, each with triplicate samples. Values are expressed as the average Miller Units ( \pm S.D.) of triplicate values.

not sufficiently strong compared with the interaction between COUP-TFI(55-423) and Ubc9 (lane 1 in Fig. 2G).

\section{COUP-TFI interacts with Ubc9 in vitro}

To confirm that Ubc9 and COUP-TFI interact directly, we performed in vitro GST pulldown assays. The GST protein and its fusion protein GST-Ubc9 were bacterially expressed, purified and incubated with in vitro-translated ${ }^{35} \mathrm{~S}$ methionine-labeled COUP-TFI proteins, as described in Materials and methods. As reported previously (Cooney et al. 1992), in vitro-translated COUP-TFI(1-423) produced two bands, as a result of two different translation start sites (Fig. 3A). Both GST-Ubc9 and GST-Ubc9(C93S) proteins inter- acted significantly with both COUP-TFI(1-423) and COUP-TFI(55-423), whereas GST-Ubc9(158) failed to interact with both COUP-TFI proteins, suggesting that deletion of the $\mathrm{N}$-terminal 54 amino acids has little effect on the interaction of GOUP-TFI with Ubc9 and that SUMOylation activity of Ubc9 is not mandatory for interaction with COUP-TFI. Indeed, our attempts to detect a SUMO-1-modified COUP-TFI protein have not yielded results to support the presence of such a COUP-TFI form (data not shown). In contrast, GST alone is unable to interact with wild-type COUP-TFI(1-423) or N-terminal-deleted COUPTFI(55-423). These results confirmed the interaction results obtained with yeast. In addition, COUP-TFI fragments encoding amino acids 1-403 and 154-403 interacted strongly with GST-Ubc9; 


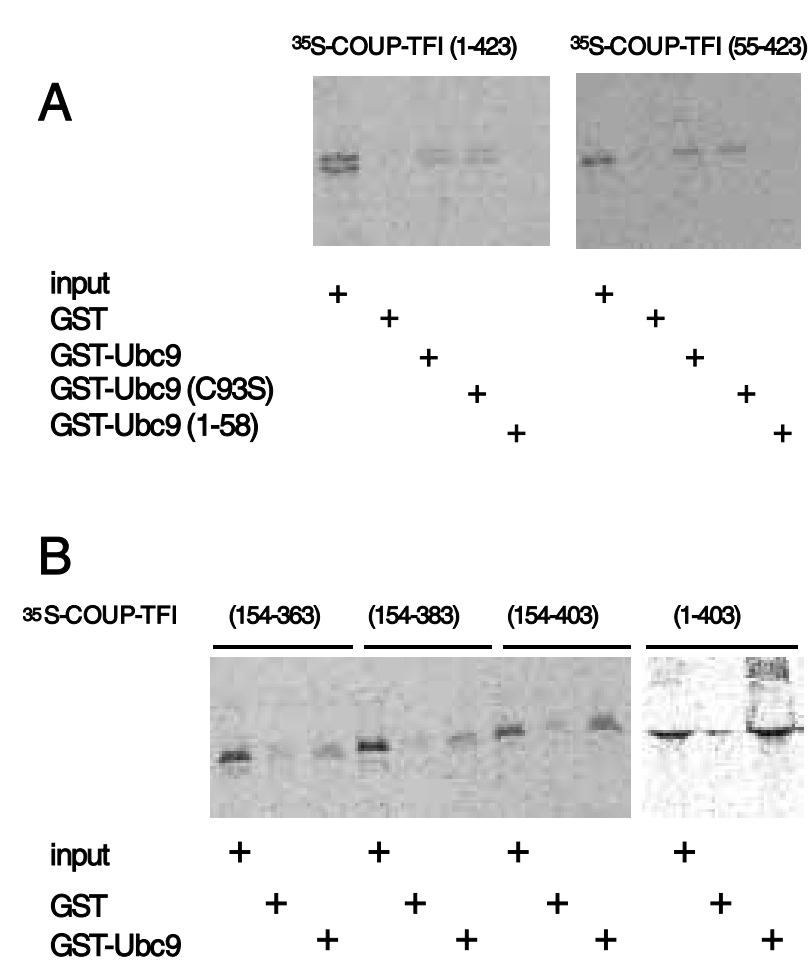

Figure 3 Ubc9 interacts directly with COUP-TFI in GST pulldown assays. (A) Interaction between ${ }^{35} \mathrm{~S}$-labeled COUP-TFI(1-423) or COUP-TFI(55-423) and

GST-Ubc9, GST-Ubc9(C93S) or GST-Ubc9(1-58).

Input is $20 \%$ of the labeled protein used in the assays. The bound ${ }^{35} \mathrm{~S}$-COUP-TFI proteins were visualized by phosphorimaging. (B) Interaction between ${ }^{35} \mathrm{~S}$-labeled COUP-TFI(1-403), COUP-TFI(154-403),

COUP-TFI(154-383) or COUP-TFI(154-363) and GST-Ubc9. Input is $20 \%$ of the labeled protein used in the assays. The bound ${ }^{35} \mathrm{~S}$-COUP-TFI proteins were visualized by phosphorimaging.

however, COUP-TFI fragments encoding amino acids 154-383 and 154-363 showed little interaction with GST-Ubc9 (Fig. 3B). These findings indicate that the COUP-TFI domain encoding amino acids 383-403 is important for interaction with Ubc9, data that are well compatible with yeast interaction data.

\section{Interaction and subcellular localization of Ubc9 and COUP-TFI in mammalian cells}

The association between COUP-TFI and Ubc9 was further investigated by coimmunoprecipitation assays (Figs 4A-C). COS-1 cells were transfected with Xpress-tagged Ubc9 (pcDNA3.1/His-
Ubc9) and RSV promoter-driven COUP-TFI expression vectors (pRSV-COUP-TFI). Polyclonal anti-COUP-TFI antibody was first used to precipitate the protein complexes containing COUP-TFI, and the presence of Ubc9 protein in these complexes was subsequently examined by immunoblotting with a polyclonal anti-Xpress antibody. The presence of Ubc9 protein was detected in lysates from cells transfected with both RSV-COUP-TFI (pRSV-COUP-TFI) and Xpress-tagged Ubc9 (pcDNA31/His-Ubc9), but not with RSV-COUP-TFI or Xpress-tagged Ubc9 alone (Fig. 4A). These findings indicate that COUP-TFI interacts with Ubc9 in mammalian cells. Taken together with interaction data (Figs 2-4), these findings show that Ubc9 interacts specifically and directly with COUP-TFI.

In order to determine if Ubc9 and COUP-TFI could interact within a cellular environment, COS-1 cells were transfected with EGFP, EGFPtagged Ubc9, EGFP-tagged Ubc9(C93S), DsRed, or DsRed-tagged COUP-TFI alone or in various combinations and photographed using a fluorescence microscope (Figs 4D-I). COS-1 cells transfected with EGFP alone displayed a diffuse green fluorescence (data not shown). EGFP-tagged Ubc9 and EGFP-tagged Ubc9(C93S) showed localization in both nucleus and cytoplasm (Figs 4D and G). COS-1 cells transfected with DsRed alone displayed a diffuse red fluorescence, whereas cells transfected with DsRed-tagged COUP-TFI showed predominantly nuclear localization with occasional dot formation. When cells were then cotransfected with both EGFP-tagged Ubc9 and DsRed-tagged GOUP-TFI, expression of both EGFP-Ubc9 and DsRed-COUP-TFI was colocalized in the nucleus and was not altered compared with the expression obtained when either was transfected alone (Figs 4D-F). In addition, expression of both EGFPtagged Ubc9(C93S) and DsRed-COUP-TFI was colocalized in the nucleus (Figs 4G-I).

\section{COUP-TFI-mediated transcriptional repression is potentiated by Ubc9 independently of the SUMO-1 conjugating activity}

To examine the influence of Ubc9 overexpression on COUP-TFI-mediated transcriptional repression, COS-1 cells were transiently transfected with expression plasmids for Gal4 DBD-COUPTFI and Ubc9 and the reporter construct 
IP: anti-COUP-TF, Blot: anti-Xpress

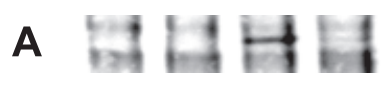

B

Blot: anti-COUP-TF

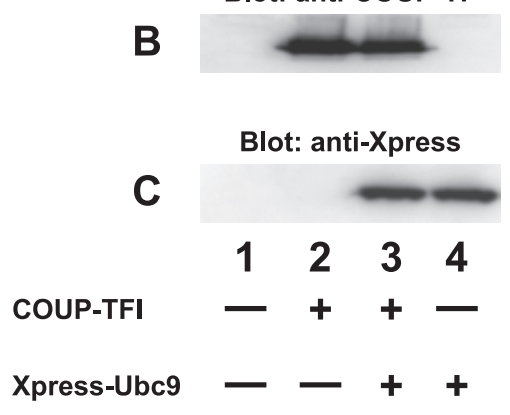

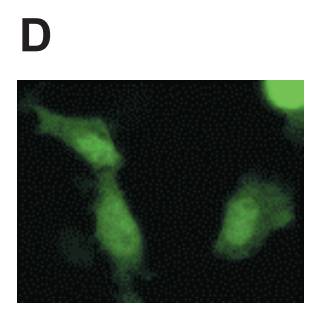

EGFP-Ubc9

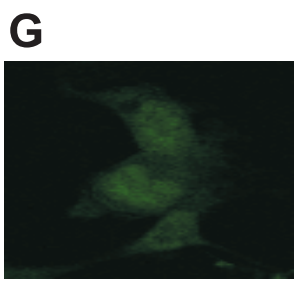

EGFP-Ubc9(C93S)

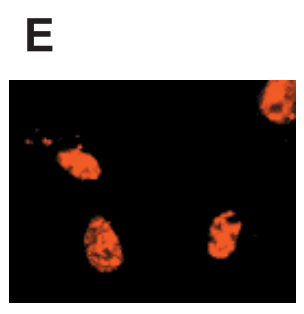

DsRed-COUP-TFI

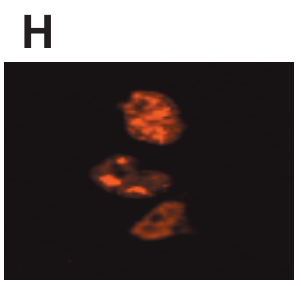

DsRed-COUP-TFI

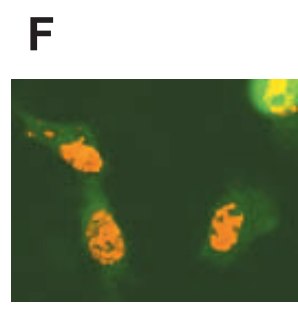

Merge

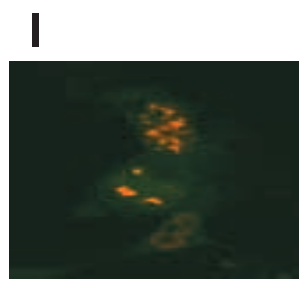

Merge

Figure 4 Ubc9 and COUP-TFI are associated and colocalized in the nuclei of transfected COS-1 cells. (A-C) Coimmunoprecipitation assays. COS-1 cells were transfected with pRSV-COUP-TFI or pXpress-Ubc9 expression constructs [pcDNA3.1/His-Ubc9(1-158)], or both, and the amount of DNA was kept constant by the addition of empty expression vectors. (A) Whole-cell extracts were subjected to immunoprecipitation (IP) with anti-COUP-TF antibody, and immunoprecipitates were subsequently analysed by immunoblotting (Blot) with anti-Xpress antibody. Immunoblots (Blot) of whole-cell extracts were transfected by various expression constructs as indicated by (B) anti-COUP-TF and (C) anti-Xpress antibodies. (D-I) Subcellular localization of Ubc9 and COUP-TFI. (D-F) EGFP-Ubc9 or (G-I) EGFP-Ubc9(C93S) was cotransfected with DsRed-COUP-TFI in COS-1 cells. These proteins are colocalized in the nuclei of the transfected COS-1 cells.

containing $4 \times$ Gal4 binding sites-thymidine kinase promoter-linked luciferase reporter DNA $(4 \times$ Gal4-tk-Luc). Transfection of a Gal4 DBD fused to the COUP-TFI(155-423) cDNA, designated as Gal4-COUP-TFI, significantly repressed basal promoter activity of the reporter gene, as shown previously (lane 5 in Fig. 5A) (Leng et al. 1996, Shibata et al. 1997a). In addition, coexpression of wild-type Ubc9 or mutant Ubc9(C93S) potentiated the repressor function of Gal4-COUPTFI in a dose-dependent manner in COS-1 cells (lanes 6-9 in Fig. 5A), whereas coexpression of mutant $\mathrm{Ubc} 9(1-58)$, which is not able to interact with COUP-TFI, did not affect the reporter activity (lanes 10-11 in Fig. 5A). Ubc9 had no significant effect on the transcription activity of the reporter construct in the absence of Gal4-COUP-TFI (lanes 1-4 in Fig. 5A). The ability of Ubc9 to potentiate the repression activity of COUP-TFI is specific, as coexpression of Ubc9 did not affect the activity of a reporter construct with no Gal4 binding sites (tk-Luc) (data not shown). When Gal4 DNAbinding domain fused to VP16 (Gal4-VP16) was overexpressed, strong activation activity of a reporter gene $(4 \times$ Gal4-tk-Luc) was observed (Fig. $5 \mathrm{~B})$. Moreover, overexpression of Ubc9 did not affect the transcription activity of Gal4-VP16 (Fig. 5B), suggesting that Ubc9 does not show nonspecific repression activity. These findings suggest that Ubc9 can function as a corepressor for COUP-TFI-mediated repression activity and that SUMO-1-conjugating activity of Ubc9 is not mandatory for COUP-TFI-mediated repression activity. The decrease in reporter gene activity was not the result of an increased cellular concentration of COUP-TFI, because immunoblots did not show alterations in immunoreactive COUP-TFI protein content (data not shown). Coexpression of Ubc9 did not increase the DNA binding of COUP-TFI, because the amount of the receptor interacting with the CRS2 element from the bovine CYP17 promoter in an electrophoretic mobility shift assay remained constant (data not shown).

The COUP-TFI mutant, COUP-TFI $\Delta 35(1-$ 388) does not contain a repressor domain (the C-terminal 35 amino acids) as shown previously (Leng et al. 1996, Shibata et al. 1997a, 2003b). Overexpression of Gal4-COUP-TFI $\Delta 35$ showed 

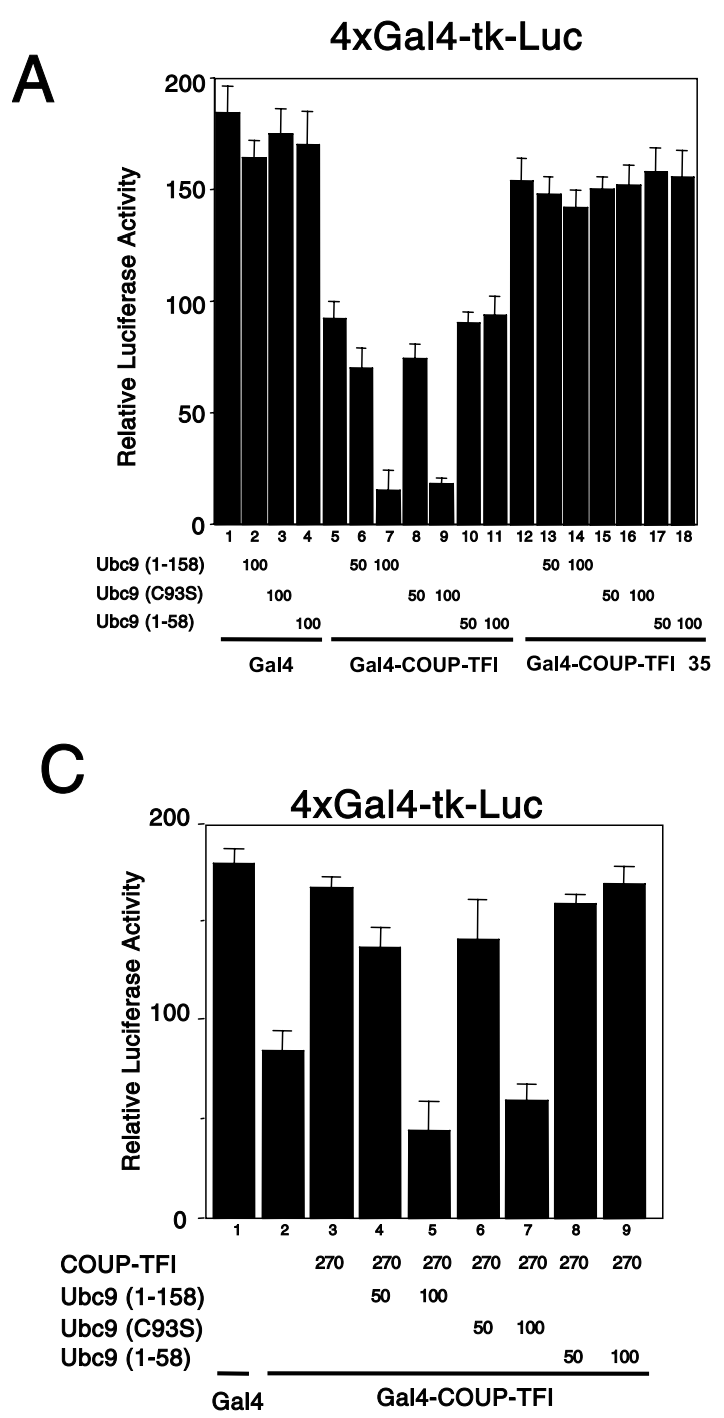

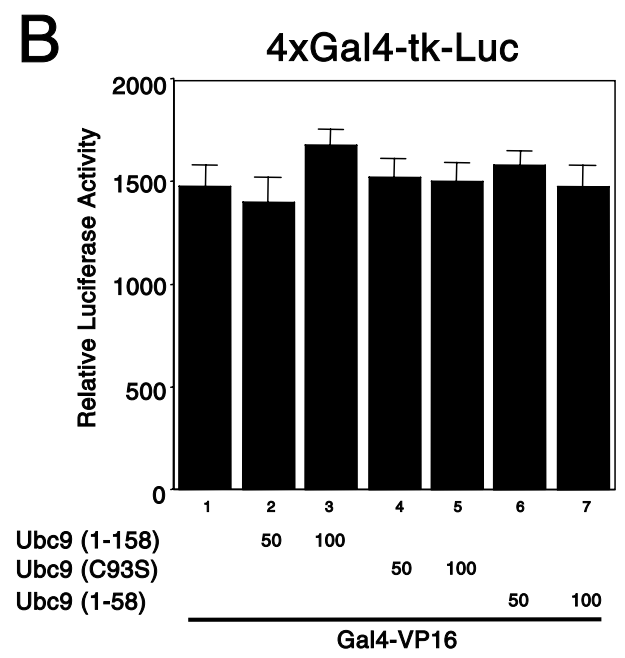

D

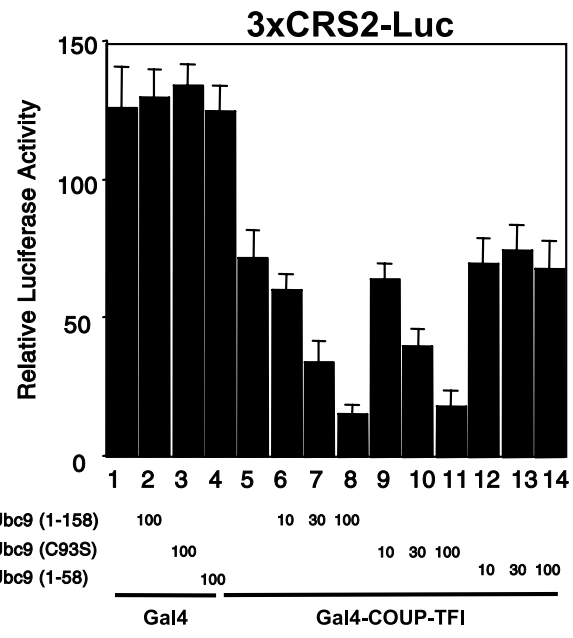

Figure 5 Ubc9 potentiates basal repression activity of Gal4-COUP-TFI or COUP-TFI in COS-1 cells. (A) COS-1 cells were transfected with $0.43 \mu \mathrm{g}$ total DNA including $30 \mathrm{ng}$ Gal4 (lanes 1-4), Gal4-COUP-TFI (lanes 5-11), or Gal4-COUP-TFI $\triangle 35$ cDNA (lanes 12-18), $0.3 \mu \mathrm{g} 4 \times$ Gal4-tk-luciferase reporter DNA, and increasing amounts of Ubc9 or mutant expression plasmids (50 and $100 \mathrm{ng}$ ) for each well of the 24-well dish as indicated. (B) Experiments similar to those in Fig. 5A were performed, except that Gal4-VP16 was used instead of Gal4-COUP-TFI. COS-1 cells were transfected with $0.41 \mu \mathrm{g}$ total DNA including $10 \mathrm{ng}$ Gal4-VP16 cDNA, $0.3 \mu \mathrm{g} 4 \times$ Gal4-tk-luciferase reporter DNA, and increasing amounts of the Ubc9 expression plasmids (50 and $100 \mathrm{ng}$ ) for each well of the 24-well dish as indicated. (C) Reversal of COUP-TFI-mediated squelching of the basal repression activity of Gal4-COUP-TFI by Ubc9. COS-1 cells were transfected with $0.7 \mu \mathrm{g}$ total DNA including $30 \mathrm{ng}$ Gal4 or Gal4-COUP-TFI cDNA, $0.3 \mu \mathrm{g}$ $4 \times$ Gal4-tk-luciferase reporter DNA, $0.27 \mu \mathrm{g}$ COUP-TFI cDNA, and increasing amounts of the Ubc9 expression plasmids (50 and $100 \mathrm{ng}$ ) for each well of the 24-well dish as indicated. (D) COS-1 cells were transfected with $0.43 \mu \mathrm{g}$ total DNA including $30 \mathrm{ng}$ pRSV or pRSV-COUP-TFI cDNA, $0.3 \mu \mathrm{g} 3 \times$ CRS2-SV40-luciferase reporter DNA (pGL3-3 CRS2), and increasing amounts of Ubc9 or mutant expression plasmids (30 and $100 \mathrm{ng}$ ) for each well of the 24-well dish as indicated. Assays were performed in three separate experiments, each with triplicate samples.

no significant effects on Gal4-responsive reporter activities and coexpression of Ubc9 did not repress the Gal4-COUP-TFI $\Delta 35$-mediated activities (lanes $12-18$ in Fig. 5A).
As shown previously (Shibata et al. 1997a), overexpression of COUP-TFI can squelch the repressor activity of a reporter gene $(4 \times$ Gal4-tkLuc) mediated by Gal4-COUP-TFI (lane 3 in 
Fig. 5C). If Ubc9 is a limiting factor required for COUP-TFI-mediated repression, overexpression of Ubc9 should reverse this squelching activity. Overexpression of wild-type Ubc9 or Ubc9(C93S), relieved the squelching of COUP-TFI on Gal4COUP-TFI repression function in a dosedependent manner (lanes 4-7 in Fig. 5C), but mutant Ubc9(1-58) did not (lanes 8-9 in Fig. 5C). We also examined the effect of Ubc9 on another COUP-TF-responsive reporter plasmid containing three copies of COUP-TF binding elements from the bovine CYP17 gene ( $3 \times$ CRS2-SV40-Luc) (Bakke \& Lund 1995, Shibata et al. 2003a,b). The results showed that coexpression of wild-type Ubc9 or mutant $\mathrm{Ubc} 9(\mathrm{C} 93 \mathrm{~S})$ potentiated the repressor function of COUP-TFI in COS-1 cells in a dose-dependent manner (Fig. 5D). However, Ubc9 did not affect the activities of the reporter in the absence of cotransfected COUP-TFI (lanes 1-4 in Fig. 5D). These findings confirm that Ubc9 can function as a corepressor for COUP-TFI-mediated repression activity in mammalian cells.

\section{Ubc9 contains intrinsic repression domains}

Corepressors can inhibit the activity of nuclear receptors by several mechanisms. The nuclear receptor corepressors $\mathrm{N}-\mathrm{CoR}$ and SMRT have been shown to repress the basal activity of promoters when they are recruited as Gal4 DNA binding domain fusion proteins. We therefore tested the intrinsic, transferable repression activity of Ubc9 in this manner and found that the Ubc9-Gal4 DNA binding domain fusion protein repressed the thymidine kinase (tk) promoter with four upstream Gal4 binding sites. Thus Ubc9 has the ability to repress promoters by recruitment alone.

Gal4 DNA binding domain fusions were also generated with Ubc9(1-58), Ubc9(1-75), Ubc9(189), Ubc9(1-100), Ubc9(59-158) and Ubc9(76$158)$ to determine which region(s) retained the intrinsic repression activity of the entire protein (Figs 1, 6A and 6B). Most of these proteins, except Ubc9(90-158) were able to repress the Gal4-tkLuc reporter (Fig. 6A), indicating that the region encompassing amino acids 1-89 functions as the transcriptional repression domain of Ubc9. In addition, the C93S mutation of Ubc9 fused to the Gal4 DNA binding domain continued to repress the Gal4-tk-Luc reporter activity to a level similar to that of the wild-type Ubc9, indicating that the SUMO-1 conjugating activity is not required for transcriptional repression activity.

Because it is very important to elucidate the complex of transcription factors that interact with Ubc9 in mammalian cells, we first examined the effect of trichostatin A (TSA), a histone deacetylase inhibitor, on the transcriptional repression activity of Gal4-Ubc9(1-158). The TSA treatment of COS- 1 cells at $10^{-7} \mathrm{M}$ for 6-12 h transfected with Gal4 DNA binding domain alone (Gal4) and with Gal4-COUP-TFI significantly reversed their transcriptional activities, whereas TSA treatment at $10^{-10}-10^{-7} \mathrm{M}$ for $6-12 \mathrm{~h}$ did not affect the transcriptional repression mediated by Gal4-Ubc9 (Figs 6B and $\mathrm{C}$ ). These findings suggest that Ubc9-mediated transcriptional repression probably does not involve recruitment of TSA-sensitive histone deacetylase(s) to the chromatin template. Coimmunoprecipitation experiments and yeast two-hybrid assays showed that Ubc9 is not directly associated with histone deacetylase HDAC1, HDAC3 or mSin3 (data not shown). Transcriptional repression mediated by COUP-TFI involves HDAC-dependent and -independent mechanisms; the latter may be partly mediated by Ubc9.

\section{Tissue distribution of mRNA of Ubc9 and COUP-TFI by northern blot analysis}

We next examined the expression of Ubc9 mRNA in human endocrine tissues (Fig. 7). Three Ubc9 mRNAs, $4 \cdot 4,2.8$ and $1.5 \mathrm{~kb}$, were observed, as shown previously (Wang et al. 1996), suggesting that these are derived from alternative splicing of the Ubc9 gene.

Ubc9 mRNA is widely distributed in many endocrine tissues, such as testis, ovary and adrenal cortex, and the expression profile of Ubc9 is thus similar to that of COUP-TFI.

\section{Discussion}

In this study, we have identified and described Ubc9, which interacts with the COUP-TFI and other nuclear receptors and has several interesting properties. It has class E2 SUMO-1 conjugating enzyme activity, interacts with COUP-TFI and represses the activity of the COUP-TFs. The C93S substitution of Ubc9, which abrogates the 


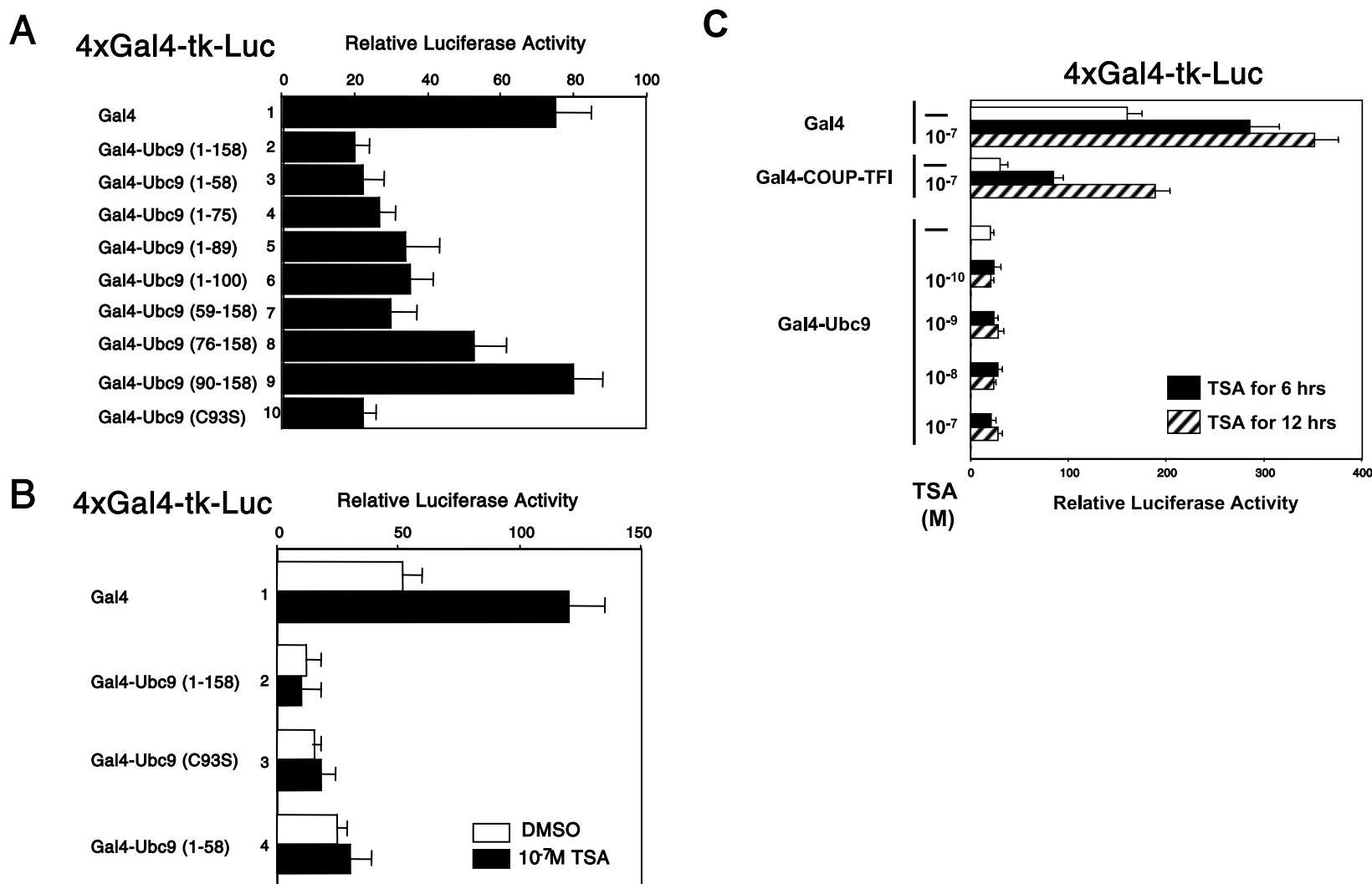

Figure 6 Autonomous transcriptional repression activity of Ubc9. (A) Autonomous transcriptional repression domains of Ubc9. Luciferase assays of extracts of COS- 1 cells transiently transfected with $0.5 \mu \mathrm{g}$ total DNA including $0.3 \mu \mathrm{g}$ $4 \times$ Gal4-tk-luciferase reporter and $0.2 \mu \mathrm{g}$ expression vectors for Gal4 DBD (pCMV-BD) or several Gal4 DBD-Ubc9 fusion proteins [Ubc9(1-158), (1-58), (1-75), (1-89), (1-100), (59-158), (76-158), (90-158) and (C93S)] for each well of the 24-well dish as indicated. Note that the quantitation shown represents the mean \pm S.D. of luciferase activity in six independent experiments. (B) Luciferase assays of extracts of COS-1 cells transiently transfected with $0.5 \mu \mathrm{g}$ total DNA including $0.3 \mu \mathrm{g} 4 \times$ Gal4-tk-luciferase reporter plasmid and $0.2 \mu \mathrm{g}$ Gal4 DBD or Gal4 DBD-Ubc9 constructs [Ubc9(1-158), (C93S) and (1-58)] for each well of the 24-well dish as indicated. Transfected COS-1 cells were exposed to $10^{-7} \mathrm{M}$ TSA $(\square)$ or DMSO $(\square)$, as indicated, for $12 \mathrm{~h}$ before harvesting and the luciferase assays. (C) Luciferase assays of extracts of COS-1 cells transiently transfected with $0.5 \mu \mathrm{g}$ total DNA including $0.3 \mu \mathrm{g}$ 4×GAl4-tk-luciferase reporter plasmid and $0.2 \mu \mathrm{g}$ Gal4, Gal4-COUP-TFI or Gal4-Ubc9 constructs for each well of the 24-well dish as indicated. Transfected COS-1 cells were exposed to $10^{-10}-10^{-7}$ M TSA or DMSO ( $\square$ ), as indicated, for $6(\square)$ or $12 \mathrm{~h}(\mathbb{Q})$ before harvesting and the luciferase assays.

SUMO-1 conjugating activity, continued to interact with COUP-TFs and to potentiate transcriptional repression mediated by COUP-TFI, indicating that its SUMO-1 conjugase and corepressor activities represent distinct and separable functions.

Ubc9 meets all the criteria for a transcriptional intermediary protein in the modulation of COUPTFI transcriptional properties. Firstly, as shown in Figs 2-4, Ubc9 specifically interacted with COUPTFI in yeast, solutions and mammalian cells. The putative ligand-binding domain of COUP-TFI is described as a transcriptional repressor domain
(Leng et al. 1996, Shibata et al. 1997a). In addition, Ubc9 was shown to interact with the region of COUP-TFI encoding amino acids 388-403, indicating that the corepressor role of Ubc9 is compatible with the properties of interaction with COUP-TFI. Secondly, overexpression of Ubc9 had no effect on the reporter activities mediated by the Gal4 DNA binding domain alone or by Gal4VP16 in COUP-TF-negative COS-1 cells. However, Ubc9 potentiated the repression activity mediated by Gal4-COUP-TFI. Subsequently, coexpression of the Ubc9 deletion mutant encoding amino acids 1-58, which impairs COUP-TFI 

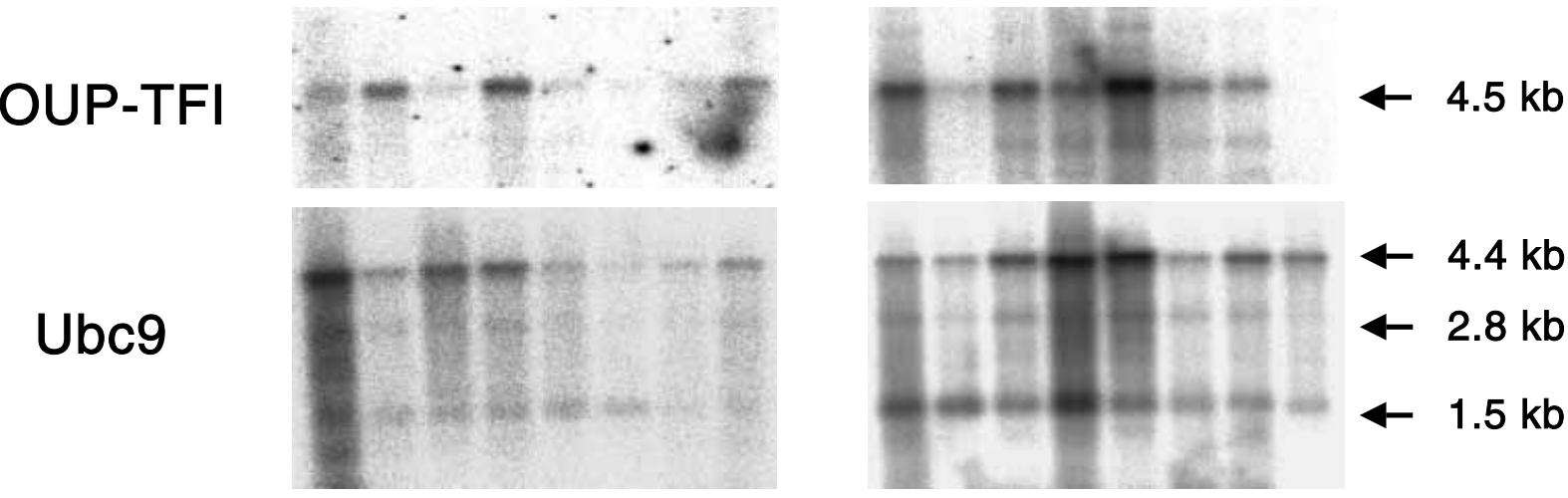

GAPDH
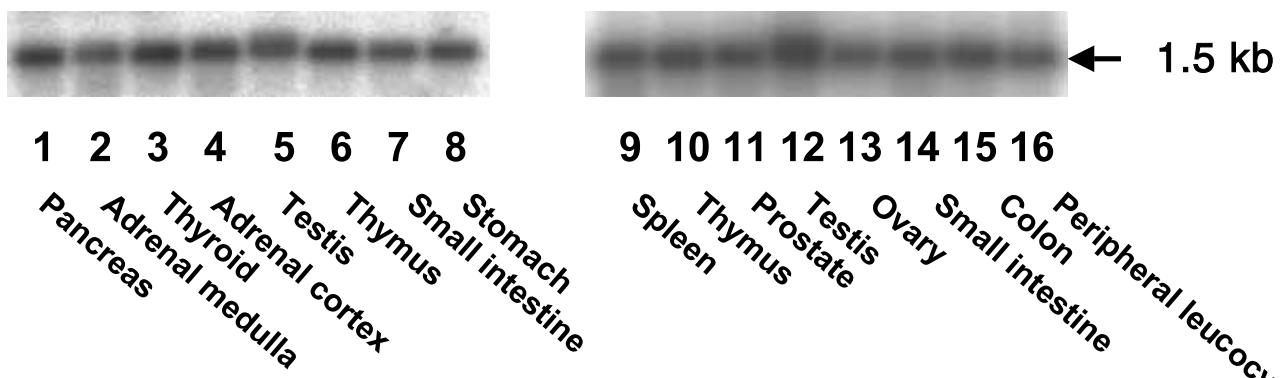

910111213141516

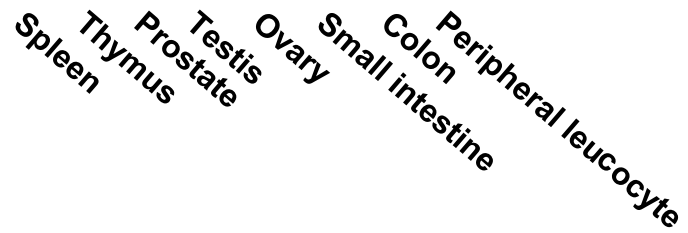

Figure 7 Tissue distribution of Ubc9 and COUP-TFI mRNA demonstrated by northern blot analyses. A human tissue northern blot (Clontech) was probed with the $1.1 \mathrm{~kb}$ hUbc9 cDNA. Each lane contained $2 \mu \mathrm{g}$ poly $(\mathrm{A})^{+}$RNA from pancreas, adrenal medulla, thyroid, adrenal cortex, testis, thymus, small intestine, stomach (lanes 1-8), spleen, thymus, prostate, testis, ovary, small intestine, colon and peripheral leucocytes (lanes 9-16). The positions of RNAs of various sizes are indicated by arrows. COUP-TFI or GAPDH cDNA was used to probe the same blot.

binding, did not affect the repressor activity mediated by Gal4-COUP-TFI, indicating that interaction of COUP-TFI with Ubc9 is required for COUP-TFI-mediated repression activity. The effect of Ubc9 on gene transcription was also confirmed in luciferase assays by using another reporter containing $3 \times$ CRS2 sequences, to which COUP-TF can bind (Bakke \& Lund 1995, Shibata et al. 2000a,b) (Fig. 5D). Thirdly, Ubc9 contained an intrinsic repressor domain when fused to the Gal4 DNA binding domain in mammalian cells. As shown in Fig. 6A, most Ubc9 fragments except the one encoding amino acids 90-158 showed intrinsic repressor activity in a dose-dependent manner, suggesting that the N-terminal Ubc9 encoding amino acids 1-89 contains transferable autonomous repressor domain. Therefore, Ubc9 is able to repress promoter activity by recruitment alone. Fourthly, overexpression of Ubc9 relieved the squelching effects of COUP-TFI on Gal4-COUPTFI repressor function, as shown in Fig. 5C, suggesting that Ubc9 is a limiting endogenous corepressor required for COUP-TFI-mediated repression. Therefore, Ubc9 possesses all the characteristics expected for a transcriptional corepressor protein of COUP-TFs in vivo.

To confirm further that Ubc9 is a corepressor of COUP-TFI, we ruled out several other possible ways in which Ubc9 might enhance COUP-TFImediated repression activity. Firstly, as SUMO-1 conjugation by Ubc9 plays an important part in protein modification, the effect of Ubc9 on COUP-TF repression activity might be the result of an effect of Ubc9 on COUP-TFI protein concentrations. Our preliminary results showed that overexpression of $\mathrm{Ubc} 9$ did not alter GOUP-TFI protein concentrations in COS-1 cells (data not shown). Secondly, it was also possible that overexpression of Ubc9 increases the concentrations of some corepressors or decreases the concentrations of some coactivators, which have been shown to interact with COUP-TFI (Pipaon et al. 1999, Sugiyama et al. 2000), but the results showed that overexpression of Ubc9 did not alter the protein concentrations of SMRT, SRG-1 and GRIP-1 in the cells (data not shown). As these 
experiments were performed by transient transfection, we are not able to conclude unequivocally that Ubc9 has no effects on these protein concentrations, and further investigation are certainly required. Thirdly, another possibility is that overexpression of Ubc9 increased the DNA-binding affinity of COUPTFI. To exclude this possibility, we carried out electrophoretic mobility shift assays to determine whether or not bacterially or in vitro transcriptiontranslated Ubc9 protein affects the binding of COUP-TFI to its response element DNA (CRS2) of the bovine CYP17 promoter region. The results indicated that Ubc9 has no effects on COUP-TFI binding to the GRS2 element. Taken together with the above mentioned data, these findings indicate that Ubc9 clearly functions as a novel corepressor of COUP-TFI in vivo.

Although COUP-TFI has been shown to interact directly with TFIIB (Tsai et al. 1987, Ing et al. 1992) in vitro, we (Shibata et al. 1997a) and others (Bailey et al. 1997) have previously shown that both N-CoR and SMRT are capable of acting as corepressors for COUP-TFI-mediated gene silencing. A number of COUP-TF-interacting proteins have recently been identified by means of a yeast two-hybrid system. In addition to N-CoR and SMRT, the COUP-TFII ligand-binding domain binds Alien (Dressel et al. 1999) and the N-CoR variant RIP13 1 corepressor proteins (Bailey et al. 1997). In the brain, COUP-TFI is coexpressed with the zinc finger proteins CTIP1 and CTIP2 (Avram et al. 2000), which bind COUP-TFI and act as corepressor proteins. Friend of GATA2 (FOG-2) (Huggins et al. 2001) has also been shown to interact selectively with the ligand-binding domain of COUP-TFI and COUP-TFII. Thus selective use of tissue-restricted corepressor proteins may be a mechanism by which COUP-TFs can induce tissue-specific transcription.

Ubc9 has several distinct properties that differ from those of the N-CoR and SMRT corepressors. Both N-CoR and SMRT have been shown to interact with both unliganded TR $\beta$ and COUPTFs (Shibata et al. 1997a). Conversely, Ubc9 has been shown to interact with COUP-TFs and SF-1, in addition to agonist-bound androgen receptor (Poukka et al. 1999, 2000) and glucocorticoid receptor (Gottlicher et al. 1996, Kaul et al. 2002), but not unliganded TR $\beta$. Therefore, the receptor selectivities of N-GoR/SMRT and Ubc9 differ considerably.
Transcriptional repression mediated by COUPTFI is enhanced by N-GoR/SMRT and by Ubc9, but the mechanisms appear to be different. The acetylation status of chromatin associated with particular genes is dependent on the activity of both histone acetyltransferases (HATs) and HDACs. The latter are primarily involved in repression of gene transcription by virtue of the compaction of chromatin structure that accompanies the removal of charge-neutralizing acetyl groups from the histone lysine tails. The next question was how Ubc9 potentiates COUP-TFImediated transcriptional repression; to answer it, TSA, a specific inhibitor of HDAC, was added in the same transfection assay (Shibata et al. 2003b, Marks et al. 2001, Hermanson et al. 2002, McKenna \& O'Malley 2002). TSA treatment was shown to reverse repression by Gal4 and Gal4-COUP-TFI, but not by Gal4-Ubc9 (Figs 6B and $\mathrm{C}$ ). These results suggest that Ubc9 exerts its repressive effects on target gene promoters by a mechanism distinct from those previously described for nuclear hormone receptors, such as TR or RAR. As COUP-TF has been shown to associate with HDACs through its C-terminal repression domain (Smirnov et al. 2000), both HDACdependent and HDAC-independent mechanisms have crucial roles in the transcriptional repression mediated by COUP-TFI, the latter being partly mediated by recruitment of Ubc9. As shown in Fig. 6C, Gal4-COUP-TFI-mediated transcription is still repressed by approximately $50 \%$ as compared with Gal4-mediated transcription; therefore we presume that COUP-TFI-mediated transcriptional repression function is exerted through TSA-sensitive HDAC complexes including N-GoR and SMRT, in addition to TSA-insensitive HDAC complexes, including Ubc9 complexes. Nevertheless, detailed mechanisms remain to be clarified in future studies. There is also another example of a COUP-TF corepressor protein, CTIP1/Evi9/B cell leukaemia 11a (Avram et al. 2000), which has a repression function that appears to be independent of TSA-sensitive HDACs. These findings suggest that alternative mechanisms, perhaps recruitment of members of the TSAinsensitive and $\mathrm{NAD}^{+}$-dependent HDACs of the silent information regulator 2 (Sir2) family (Imai et al. 2000) or association with heterochromatin, or both, may underlie the corepression mechanisms. 
In contrast, the transcriptional properties of Ubc9 have some similarities to those of N-CoR and SMRT, namely bifunctional coactivator and corepressor functions. Ubc9 has been shown to act as a coactivator-like protein of androgen receptor (Poukka et al. 1999, 2000) and glucocorticoid receptor in a hormone-sensitive manner (Gottlicher et al. 1996, Kaul et al. 2002), and thus Ubc9 appears to be a bifunctional coregulator with both coactivator and corepressor functions, depending on the receptor and the promoter contexts. Similarly, SMRT previously identified as a corepressor is shown to function as a coactivator for TR from a negative hormone response element. The mechanisms for the bifunctional role are unknown; however, the role of the allosteric effects of DNA on the transcription factors that bind to it has been reported. Three other examples of bifunctional coregulators, NSDl (Huang et al. 1998), FKHR (Zhao et al. 2001) and Zaclb (Huang \& Stallcup 2000), have been reported which can regulate transcription either positively or negatively, depending on both the promoter context and the cell type.

Attachment of SUMO is a dynamic and reversible process, requiring a multi-step reaction catalysed by specific enzymes related to, but distinct from, enzymes involved in ubiquitination. The specific SUMO-1 conjugating enzyme is called Ubc9 and is necessary for protein substrate recognition and SUMO-1 linkage, which explains why numerous Ubc9-interacting proteins proved to be substrates for SUMO-1. However, a large number of proteins shown to interact with Ubc9 in the yeast two-hybrid system have not been found to be SUMOylated.

The next question was whether SUMOylation is related to corepressor function. As SUMO-1 is transferred at the Cys93 residue by a class E1 enzyme and replacement of the residue disrupts SUMO-1 binding to Ubc9, introduction of the C93S substitution into the protein-coding sequence of Ubc9 rendered it incapable of SUMO-1 conjugation (Chakrabarti et al. 1999, Poukka et al. 1999, 2000). The C93S mutant of Ubc9 only marginally attenuated the interaction with COUPTFI (Fig. 2B), COUP-TFII and SF-1 (data not shown), and thus the SUMO-1 conjugating ability of Ubc9 is not required for interaction with COUP-TFI. In addition, the C93S mutant of Ubc9 continued to potentiate repression activity mediated by COUP-TFI and Gal4-COUP-TFI, to almost the same extent as wild-type Ubc9. These findings suggest that Ubc9 can function as a corepressor for COUP-TF in a manner that is independent of its SUMOylation activity. However, these findings do not exclude a possibility that COUP-TFI can be SUMOylated by Ubc9 and class E3 SUMO-1 ligase PIAS1. There are no SUMOylation consensus motifs in the human COUP-TFI and our preliminary data indicated that COUP-TFI was not SUMOylated in vitro and in vivo, but details of the relationship between SUMOylation and transcriptional corepressor activities remain to be elucidated.

Recent data have raised the intriguing possibility that SUMO modification may have a specific impact on the ability of some transcription factors to function synergistically (Iniguez-Lluhi \& Pearce 2000, Le Drean et al. 2002, Verger et al. 2003). Previous studies of the glucocorticoid receptor had identified a region referred to as a synergy control (SC) motif, mutation of which led to a selective increase in the activity of the glucocorticoid receptor from promoters bearing multiple, but not single, sites. The SC motif contains a consensus SUMO acceptor site, and recent data have shown that this is, in fact, the major site of addition of SUMO in the glucocorticoid receptor. It was originally proposed that the presence of multiple SG motifs (now known to encompass SUMOylation sites) allows for the recruitment of a putative SG factor that attenuates synergistic activation (Iniguez-Lluhi \& Pearce 2000, Le Drean et al. 2002). Recent findings suggest that the negative factor is likely to be SUMO, or potentially the E2 conjugase Ubc9, which is capable of binding SUMO consensus sites. As there are no SUMO consensus sites in COUP-TFI, and overexpression of SUMO-1 did not affect the COUP-TFImediated transcriptional activity (data not shown), the role of SUMO-1 for COUP-TFI remains unknown. Similarly, the SUMO E2 enzyme Ubc9, which interacts with the androgen receptor and with the transcriptional repressor TEL, seems to regulate their activities independently of its SUMO E2 enzyme activity. It is possible that proteins associated with COUP-TFI may be targeted by SUMOylation; these SUMO substrates need to be identified. Indeed, there are SUMO consensus sites in several HDAGs, and SUMOylation is crucial for the expression of HDAG activities (David et al. 2002, Kirsh et al. 2002). 
Ubc9 has been shown to be essential both for cell viability and for SUMO-1 conjugase. Hayashi et al. (2002) showed that a considerable portion of the Ubc9-depleted cell population was committed to apoptosis without accumulating in a specific phase of the cell cycle, suggesting that chromosome damage accumulates in Ubc9-depleted cells.

Ubc9 is highly expressed in steroidogenic tissues such as the adrenal cortex, testis and ovary. In addition, it has been shown to interact not only with COUP-TFs but also with SF-1, indicating that Ubc9 together with COUP-TFs and SF-1 have an important role in steroidogenesis of the adrenal cortex. We found that Ubc9 can function as a corepressor of COUP-TFI-mediated repression of the CYP17 gene that is a key enzyme for glucocorticoid and adrenal androgen synthesis. We also found that Ubc9 was highly expressed in the nuclei of the normal adrenal cortex, in addition to adrenocortical adenomas (data not shown). We are currently investigating the pathophysiological importance of Ubc9 for COUP-TFI and SF-1 in adrenocortical tumours.

Collectively, our results suggest that Ubc9 functions as a novel COUP-TFI corepressor, the function of which is distinct and separable from its SUMO-1 conjugating enzyme activity. Further investigation is needed to explore the mechanistic role of SUMO-1 in COUP-TFImediated transcription.

\section{Acknowledgements}

We thank Ken-ichirou Morohashi and Masaru Murai for generously supplying research materials. We thank Drs Ming-Jer Tsai, Sophia Tsai and Bert W O'Malley for supplying plasmids and for critical review of the manuscript. This work was supported by a Grant-in-Aid for Scientific Research (C) from Japan Society for the Promotion of Science (No. 14571072 2002-4) (to HS), by a Grant-in-Aid for Scientific Research (B) from the Ministry of Education, Science, Sports and Culture (No. 1347219 2001-3) (to TS), by a Grant for the Promotion of the Advancement of Education and Research in Graduate Schools (to TS), and by a Grant-in-Aid for Research Project for Disorders of Adrenocortical Hormone Production from the Ministry of Health, Labour and Welfare, Japan (to $\mathrm{TS}$.

\section{References}

Achatz G, Holzl B, Speckmayer R, Hauser C, Sandhofer F \& Paulweber B 1997 Functional domains of the human orphan receptor ARP-1/COUP-TFII involved in active repression and transrepression. Molecular and Cellular Biology 17 4914-4932.

Avram D, Fields A, Pretty On Top K, Nevrivy DJ, Ishmael JE \& Leid M 2000 Isolation of a novel family of $\mathrm{C}(2) \mathrm{H}(2)$ zinc finger proteins implicated in transcriptional repression mediated by chicken ovalbumin upstream promoter transcription factor (COUP-TF) orphan nuclear receptors. Fournal of Biological Chemistry 275 10315-10322.

Bailey PJ, Dowhan DH, Franke K, Burke LJ, Downes M \& Muscat GE 1997 Transcriptional repression by COUP-TF II is dependent on the C-terminal domain and involves the N-CoR variant, RIP13 delta1. Fournal of Steroid Biochemistry and Molecular Biology 63 $165-174$.

Bakke M \& Lund J 1995 Mutually exclusive interactions of two nuclear orphan receptors determine activity of a cyclic adenosine $3^{\prime}, 5^{\prime}$-monophosphate-responsive sequence in the bovine CYP17 gene. Molecular Endocrinology 9 327-339.

Berrodin TJ, Marks MS, Ozato K, Linney E \& Lazar MA 1992 Heterodimerization among thyroid hormone receptor, retinoic acid receptor, retinoid $\mathrm{X}$ receptor, chicken ovalbumin upstream promoter transcription factor, and an endogenous liver protein. Molecular Endocrinology 6 1468-1478.

Casanova J, Helmer E, Selmi-Ruby S, Qi JS, Au-Fliegner M, Desai-Yajnik V, Koudinova N, Yarm F, Raaka BM \& Samuels HH 1994 Functional evidence for ligand-dependent dissociation of thyroid hormone and retinoic acid receptors from an inhibitory cellular factor. Molecular and Cellular Biology 14 5756-5765.

Chakrabarti SR, Sood R, Ganguly S, Bohlander S, Shen Z \& Nucifora G 1999 Modulation of TEL transcription activity by interaction with the ubiquitin-conjugating enzyme UBC9. Proceedings of the National Academy of Sciences of the United States of America 96 7467-7472.

Cooney AJ, Tsai SY, O'Malley BW \& Tsai MJ 1992 Chicken ovalbumin upstream promoter transcription factor (COUP-TF dimers bind to different GGTCA response elements, allowing COUP-TF to repress hormonal induction of the vitamin D3, thyroid hormone, and retinoic acid receptors. Molecular and Cellular Biology 12 4153-4163.

Cooney AJ, Leng X, Tsai SY, O’Malley BW \& Tsai MJ 1993 Multiple mechanisms of chicken ovalbumin upstream promoter transcription factor-dependent repression of transactivation by the vitamin $\mathrm{D}$, thyroid hormone, and retinoic acid receptors. Fournal of Biological Chemistry 268 4152-4160.

Cooney AJ, Lee CT, Lin SC, Tsai SY \& Tsai MJ 2001 Physiological function of the orphans GCNF and COUP-TF. Trends in Endocrinology and Metabolism 12 247-251.

David G, Neptune MA \& DePinho RA 2002 SUMO-1 modification of histone deacetylase 1 (HDAC1) modulates its biological activities. Fournal of Biological Chemistry 277 23658-22363.

Desterro JM, Rodriguez MS \& Hay RT 1998 SUMO-1 modification of IkappaBalpha inhibits NF-kappaB activation. Molecular Cell $\mathbf{2}$ 233-239.

Dressel U, Thormeyer D, Altincicek B, Paululat A, Eggert M, Schneider S, Tenbaum SP, Renkawitz R \& Baniahmad A 1999 Alien, a highly conserved protein with characteristics of a corepressor for members of the nuclear hormone receptor superfamily. Molecular and Cellular Biology 19 3383-3394.

Durfee T, Becherer K, Chen PL, Yeh SH, Yang Y, Kilburn AE, Lee WH \& Elledge SJ 1993 The retinoblastoma protein associates with the protein phosphatase type 1 catalytic subunit. Genes and Development 7 555-569.

Goodson ML, Hong Y, Rogers R, Matunis MJ, Park-Sarge OK \& Sarge KD 2001 Sumo-1 modification regulates the DNA binding 
activity of heat shock transcription factor 2, a promyelocytic leukemia nuclear body associated transcription factor. Fournal of Biological Chemistry 276 18513-18518.

Gottlicher M, Heck S, Doucas V, Wade E, Kullmann M, Cato AC, Evans RM \& Herrlich P 1996 Interaction of the Ubc9 human homologue with c-Jun and with the glucocorticoid receptor. Steroids 61 257-262.

Hardeland U, Steinacher R, Jiricny J \& Schar P 2002 Modification of the human thymine-DNA glycosylase by ubiquitin-like proteins facilitates enzymatic turnover. EMBO fournal 21 1456-1464.

Hay RT 2001 Protein modification by SUMO. Trends in Biochemical Sciences 26 332-333.

Hayashi T, Seki M, Maeda D, Wang W, Kawabe Y, Seki T, Saitoh H, Fukagawa T, Yagi H \& Enomoto T 2002 Ubc9 is essential for viability of higher eukaryotic cells. Experimental Cell Research $\mathbf{2 8 0}$ 212-221.

Hermanson O, Glass CK \& Rosenfeld MG 2002 Nuclear receptor coregulators: multiple modes of modification. Trends in Endocrinology and Metabolism 13 55-60.

Hochstrasser M 2001 Sp-ring for SUMO. New functions bloom for a ubiquitin-like protein. Cell $\mathbf{1 0 7} 5-8$.

Hoege C, Pfander B, Moldovan GL, Pyrowolakis G \& Jentsch S 2002 RAD6-dependent DNA repair is linked to modification of PCNA by ubiquitin and SUMO. Nature 419 135-141.

Huang N, vom Baur E, Garnier JM, Lerouge T, Vonesch JL, Lutz Y, Chambon P \& Losson R 1998 Two distinct nuclear receptor interaction domains in NSD1, a novel SET protein that exhibits characteristics of both corepressors and coactivators. EMBO fournal 17 3398-3412.

Huang SM \& Stallcup MR 2000 Mouse Zac1, a transcriptional coactivator and repressor for nuclear receptors. Molecular and Cellular Biology 20 1855-1867.

Huggins GS, Bacani CJ, Boltax J, Aikawa R \& Leiden JM 2001 Friend of GATA 2 physically interacts with chicken ovalbumin upstream promoter-TF2 (COUP-TF2) and COUP-TF3 and represses COUP-TF2-dependent activation of the atrial natriuretic factor promoter. Fournal of Biological Chemistry 276 28029-28036.

Imai S, Armstrong CM, Kaeberlein M \& Guarente L 2000 Transcriptional silencing and longevity protein Sir2 is NAD-dependent histone deacetylase. Nature 403 795-800.

Ing NH, Beekman JM, Tsai SY, Tsai MJ \& O'Malley BW 1992 Members of the steroid hormone receptor superfamily interact with TFIIB (S300-II). Fournal of Biological Chemistry 267 17617-17623.

Iniguez-Lluhi JA \& Pearce D 2000 A common motif within the negative regulatory regions of multiple factors inhibits their transcriptional synergy. Molecular and Cellular Biology 20 6040-6050.

Jackson PK 2001 A new RING for SUMO: wrestling transcriptional responses into nuclear bodies with PIAS family E3 SUMO ligases. Genes and Development 15 3053-3058.

Kagey MH, Melhuish TA \& Wotton D 2003 The polycomb protein Pc2 is a SUMO E3. Cell $\mathbf{1 1 3} 127-137$.

Kahyo T, Nishida T \& Yasuda H 2001 Involvement of PIAS1 in the sumoylation of tumor suppressor p53. Molecular Cell 8 713-718.

Kaul S, Blackford JA Jr, Cho S \& Simons SS Jr 2002 Ubc9 is a novel modulator of the induction properties of glucocorticoid receptors. Fournal of Biological Chemistry 277 12541-12549.

Kim J, Cantwell CA, Johnson PF, Pfarr CM \& Williams SC 2002 Transcriptional activity of CCAAT/enhancer binding proteins is controlled by a conserved inhibitory domain that is a target for sumoylation. Fournal of Biological Chemistry 277 38037-38044.

Kirsh O, Seeler JS, Pichler A, Gast A, Muller S, Miska E, Mathieu M, Harel-Bellan A, Kouzarides T, Melchior F \& Dejean A 2002 The SUMO E3 ligase RanBP2 promotes modification of the HDAC4 deacetylase. EMBO Journal 21 2682-2691.

Kliewer SA, Umesono K, Heyman RA, Mangelsdorf DJ, Dyck JA \& Evans RM $1992 a$ Retinoid X receptor-COUP-TF interactions modulate retinoic acid signaling. Proceedings of the National Academy of Sciences of the United States of America 89 1448-1452.

Kliewer SA, Umesono K, Noonan DJ, Heyman RA \& Evans RM $1992 b$ Convergence of 9-cis retinoic acid and peroxisome proliferator signalling pathways through heterodimer formation of their receptors. Nature $358771-774$.

Kovalenko OV, Plug AW, Haaf T, Gonda DK, Ashley T, Ward DC, Radding CM \& Golub EI 1996 Mammalian ubiquitin-conjugating enzyme Ubc9 interacts with Rad51 recombination protein and localizes in synaptonemal complexes. Proceedings of the National Academy of Sciences of the United States of America 93 2958-2963.

Ladias JA \& Karathanasis SK 1991 Regulation of the apolipoprotein AI gene by ARP-1, a novel member of the steroid receptor superfamily. Science 251 561-565.

Le Drean Y, Mincheneau N, Le Goff P \& Michel D 2002 Potentiation of glucocorticoid receptor transcriptional activity by sumoylation. Endocrinology 143 3482-3489.

Leng X, Cooney AJ, Tsai SY \& Tsai MJ 1996 Molecular mechanisms of COUP-TF-mediated transcriptional repression: evidence for transrepression and active repression. Molecular and Cellular Biology 16 2332-2340.

McKenna NJ \& O'Malley BW 2002 Combinatorial control of gene expression by nuclear receptors and coregulators. Cell $\mathbf{1 0 8}$ 465-474.

Malik S \& Karathanasis S 1995 Transcriptional activation by the orphan nuclear receptor ARP-1. Nucleic Acids Research 23 $1536-1543$.

Marks PA, Rifkind RA, Richon VM, Breslow R, Miller T \& Kelly WK 2001 Histone deacetylases and cancer: causes and therapies. Nature Reviews Cancer 1 194-202.

Matunis MJ, Wu J \& Blobel G 1998 SUMO-1 modification and its role in targeting the Ran GTPase-activating protein, RanGAP1, to the nuclear pore complex. Foumal of Cell Biology 140 499-509.

Melchior F 2000 SUMO-nonclassical ubiquitin. Annual Review of Cell and Developmental Biology 16 591-626.

Muller S, Hoege C, Pyrowolakis G \& Jentsch S 2001 SUMO, ubiquitin's mysterious cousin. Nature Reviewes Molecular Cell Biology 2 202-210.

Pereira FA, Qiu Y, Tsai MJ \& Tsai SY 1995 Chicken ovalbumin upstream promoter transcription factor (COUP-TF): expression during mouse embryogenesis. Fournal of Steroid Biochemistry and Molecular Biology 53 503-508.

Pichler A \& Melchior F 2002 Ubiquitin-related modifier SUMO1 and nucleocytoplasmic transport. Traffic 3 381-387.

Pichler A, Gast A, Seeler JS, Dejean A \& Melchior F 2002 The nucleoporin RanBP2 has SUMO1 E3 ligase activity. Cell $\mathbf{1 0 8}$ $109-120$

Pipaon C, Tsai SY \& Tsai MJ 1999 COUP-TF upregulates NGFI-A gene expression through an Spl binding site. Molecular and Cellular Biology 19 2734-2745.

Poukka H, Aarnisalo P, Karvonen U, Palvimo JJ \& Janne OA 1999 Ubc9 interacts with the androgen receptor and activates receptor-dependent transcription. Fournal of Biological Chemistry 274 19441-19446.

Poukka H, Karvonen U, Janne OA \& Palvimo JJ 2000 Covalent modification of the androgen receptor by small ubiquitin-like modifier 1 (SUMO-1). Proceedings of the National Academy of Sciences of the United States of America 97 14145-14150.

Seeler JS \& Dejean A 2001 SUMO: of branched proteins and nuclear bodies. Oncogene $207243-7249$.

Shibata H, Nawaz Z, Tsai SY, O’Malley BW \& Tsai MJ 1997a Gene silencing by chicken ovalbumin upstream promoter-transcription factor I (COUP-TFI) is mediated by transcriptional corepressors, nuclear receptor-corepressor (N-CoR) and silencing mediator for retinoic acid receptor and thyroid hormone receptor (SMRT). Molecular Endocrinololgy 11 714-724. 
Shibata H, Spencer TE, Onate SA, Jenster G, Tsai SY, Tsai MJ \& O'Malley BW 1997b Role of co-activators and co-repressors in the mechanism of steroid/thyroid receptor action. Recent Progress in Hormone Research 52 141-164.

Shibata H, Ando T, Suzuki T, Kurihara I, Hayashi K, Hayashi M, Saito I, Murai M \& Saruta T 1998 COUP-TFI expression in human adrenocortical adenomas: possible role in steroidogenesis. Fournal of Clinical Endocrinology and Metabolism 83 4520-4523.

Shibata H, Ando T, Kurihara I, Suzuki T, Lund J, Morohashi K, Sasano H, Hayashi K, Hayashi M, Saito I \& Saruta T 2000a Functional role of COUP-TFI, SF-1, and nuclear receptor coregulators in the steroidogenesis of adrenocortical adenomas, In Molecular Steroidogenesis, p 345-348. Eds M Okamoto, Y Ishimura \& H Nawata. Tokyo: Universal Academy Press, Inc.

Shibata H, Ikeda Y, Morohashi K, Mukai T, Kurihara I, Ando T, Suzuki T, Kobayashi S, Hayashi K, Hayashi M, Saito I \& Saruta T $2000 b$ Orphan receptors COUP-TF and DAX-1 as targets in disordered CYP17 expression in adrenocortical tumors. Endocrine Research 26 1039-1044.

Shibata H, Ikeda Y, Mukai T, Morohashi K, Kurihara I, Ando T, Suzuki T, Kobayashi S, Murai M, Saito I \& Saruta T 2001 Expression profiles of COUP-TF, DAX-1, and SF-1 in the human adrenal gland and adrenocortical tumors: possible implications in steroidogenesis. Molecular Genetics and Metabolism 74 206-216.

Shibata H, Kobayashi S, Kurihara I, Saito I \& Saruta T 2003a Nuclear receptors and co-regulators in adrenal tumors. Hormone Research 59 (suppl 1) 85-93.

Shibata H, Kurihara I, Kobayashi S, Yokota K, Suda N, Saito I \& Saruta T $2003 b$ Regulation of differential COUP-TF-coregulator interactions in adrenal cortical steroidogenesis. Fournal of Steroid Biochemistry and Molecular Biology 85 449-456.

Smirnov DA, Hou S \& Ricciardi RP 2000 Association of histone deacetylase with COUP-TF in tumorigenic Ad12- transformed cells and its potential role in shut-off of MHC class I transcription. Virology 268 319-328.

Sugiyama T, Wang JC, Scott DK \& Granner DK 2000 Transcription activation by the orphan nuclear receptor, chicken ovalbumin upstream promoter-transcription factor I (COUP-TFI). Definition of the domain involved in the glucocorticoid response of the phosphoenolpyruvate carboxykinase gene. Fournal of Biological Chemistry 275 3446-3454.

Tran P, Zhang XK, Salbert G, Hermann T, Lehmann JM \& Pfahl M 1992 COUP orphan receptors are negative regulators of retinoic acid response pathways. Molecular and Cellular Biology 12 4666-4676.

Tsai SY \& Tsai MJ 1997 Chick ovalbumin upstream promoter-transcription factors (COUP-TFs): coming of age. Endocrine Review 18 229-240.

Tsai SY, Sagami I, Wang H, Tsai MJ \& O'Malley BW 1987 Interactions between a DNA-binding transcription factor (COUP) and a non-DNA binding factor (S300-II). Cell 50 701-709.

Verger A, Perdomo J \& Crossley M 2003 Modification with SUMO. EMBO Report 4 137-142.

Wang LH, Tsai SY, Cook RG, Beattie WG, Tsai MJ \& O'Malley BW 1989 COUP transcription factor is a member of the steroid receptor superfamily. Nature 340 163-166.

Wang ZY, Qiu QQ, Seufert W, Taguchi T, Testa JR, Whitmore SA, Callen DF, Welsh D, Shenk T \& Deuel TF 1996 Molecular cloning of the cDNA and chromosome localization of the gene for human ubiquitin-conjugating enzyme 9. Fournal of Biological Chemistry 271 24811-24816.

Wilson VG \& Rangasamy D 2001 Intracellular targeting of proteins by sumoylation. Experimental Cell Research 271 57-65.

Yang SH, Bumpass DC, Perkins ND \& Sharrocks AD 2002 The ETS domain transcription factor Elk-1 contains a novel class of repression domain. Molecular and Cellular Biology 22 5036-5046.

Zhao HH, Herrera RE, Coronado-Heinsohn E, Yang MC, Ludes-Meyers JH, Seybold-Tilson KJ, Nawaz Z, Yee D, Barr FG, Diab SG, Brown PH, Fuqua SA \& Osborne CK 2001 Forkhead homologue in rhabdomyosarcoma functions as a bifunctional nuclear receptor-interacting protein with both coactivator and corepressor functions. Fournal of Biological Chemistry $\mathbf{2 7 6}$ 27907-27912.

Received in final form 15 October 2003 Accepted 10 November 2003 